\title{
Analysis of Physical and Mechanical Properties of Galvanic-Plasma Wear-Resistant Coatings
}

\author{
Mahmood Shaker Albdeiri*, Sergey Sergeev, Vladimir V. Krasilnikov \\ Belgorod state national research university, Pobedy St, 85, Belgorod 308015, Russia
}

\begin{tabular}{l} 
A R T I C L E I N F O \\
\hline Article history: \\
Received: 11 October, 2020 \\
Accepted: 07 December, 2020 \\
Online: 16 December, 2020 \\
\hline Keywords: \\
Plasma electrolytic oxidation \\
Coatings \\
Microhardness \\
Porosity \\
Phases \\
Wear resistance \\
Heat-resistance \\
Pin-on-disk \\
Tribological properties
\end{tabular}

\begin{abstract}
A B S T R A C T
This article shows the possibility of creating high wear-resistant and corrosion-resistant coating by plasma electrolytic oxidation (PEO) on the AlSi12Cu aluminum alloy. The combination of influencing parameters during processing allows to influencing of the set of quality indicators of coating, such as the thickness of the coating layer, microhardness, porosity, phase and elemental composition. The influence of technological modes and electrolyte composition on the structure and composition of the resulting coating has been established. The structural features of the modified layers was investigated, the effect of the capacitor capacitance on the installation and the duration of treatment on the structure and microhardness of the resulting coating was established. The tribological properties of the different PEO surfaces had been evaluated by usage of the 'pin-on-disk' method. Different current densities were chosen to represent the arrangement component of the PEO layer. Wear test results were used to evaluate the wear resistance ability of the various PEO layers and for establishing a wear model. The surface morphology, porosity distribution on crosssection, and worn surface of the PEO layers were characterized using a scanning electron microscope (SEM). Different material counterparts and contact conditions were applied to simulate a variety of practical states. The results show that the hardness of the PEO layer formed on sample M5 was the highest among the five kinds of samples. The PEO layer formed at sample M5 has the best wear resistance. This can be ascribed to the different size and appropriation of the pores and the diverse proportion of $\alpha$ to the $\gamma$ stage in the PEO layers when exposed to various limitations during the PEO cycle.
\end{abstract}

\section{Introduction}

During the operation of the internal combustion engine, the parts of the cylinder-piston group wear out most quickly. The wear of the cylinder-piston group of the engine takes place in conditions of high temperature, significant cyclic mechanical loads and an aggressive gas environment. One of the effective ways to increase the service life and reliability of the rotor group of an internal combustion engine is $P E O$, which leads to the formation of multifunctional wear- resistant coating based on ceramics on the working surface, which are characterized by high adhesion to the base [1].

$P E O$ is a modern promising technology for electrochemical oxidation of valve group metals, including aluminum, titanium, zirconium, magnesium, niobium, beryllium, and tantalum, as well as their alloys in order to form a uniform ceramic coating with a

*Corresponding Author: Mahmood Albdeiri, Belgorod- Russia, engmahmood86@gmail.com

WwW.astesj.com

https://dx.doi.org/10.25046/aj0506167 thickness of 80 - $300(\mu \mathrm{m})$ with high performance and protective properties. The environmentally friendly $P E O$ method is optimal for processing and hardening the surfaces of products with complex-shaped parts and limited units of the electrical, aviation, oil and gas processing industries, instrument, and mechanical engineering, as well as shipbuilding, medicine, and utilities [2, 3]. The $P E O$ method makes it possible to obtain a coating on the surface of aluminum alloys, which includes the $\gamma$ - and $\alpha$-phases of aluminum oxide, mullite (in the case of alloying the alloy with silicon). Corundum ( $\alpha$-phase) has a low coefficient of friction (0.04 and less) and low thermal conductivity, which increases the wear resistance of the friction pair, reduces heat transfer from the working chamber, and provides high corrosion resistance. Moreover, it has a higher hardness compared to the $\gamma$-phase of aluminum oxide. On the other hand, the presence of the $\gamma$-phase makes it possible to somewhat increase the coating resistance for cyclic mechanical and thermal loads. Mullite, in turn, has a low density, high thermal stability and corrosion resistance, low thermal conductivity, acceptable values of strength characteristics 
$[4,5]$. Many previous studies that have discussed the effect of coating thickness [6], solution concentrations [7], and porosity size [8] on corrosion performance and hardness. In this work, suitable thicknesses between $80-100(\mu \mathrm{m})$ were chosen to obtain high hardness. In an attempt to get the lowest possible porosity, but impossible to obtain a coating that does not contain pores, due to the nature of the process. If necessary, the porosity can be reduced by saturating the surface layer with the application of a polymer. The coating produced had the best results for the lowest possible wear rate and thus reduce the friction coefficient to a minimum.

Favorable factors for the widespread of the PEO process in the industry are a set of such advantages as the possibility of obtaining high-quality wear-resistant, heat-protective coatings in combination with sufficiently high productivity, simplicity of hardware design, environmental friendliness, and costeffectiveness of process automation [9]. The aim of the study is the influence of the parameters of the PEO process on the structure, mechanical and physical properties of the coating applied to the aluminum alloy $\mathrm{AlSi} 12 \mathrm{Cu}$ to get high wear resistance.

Also, the goal of this study was formulated: to assess the possibility of applying GPM to the aluminum alloy AK12MMGH, Modification with the help of GPM makes it possible to increase the resource and reliability of parts of the Internal Combustion Engine (ICE), also protect them from hightemperature gas erosion and reduce the temperature of the base metal by 1.5 times [10]. To work out the modes and to study the structure and properties of the obtained coatings

\section{Materials and Research Methods}

Prepared AlSi12Cu Samples for coating were made in the form of a ring with a surface area of (3.6) $\mathrm{dm}^{2}$. The external diameter size of such rings was $200 \mathrm{~mm}$ and the internal diameter was $164 \mathrm{~mm}$ and the thickness were $10 \mathrm{~mm}$. An ELS device MDO-50-AKT-001 was used to form the coating. Two regimes were used to start the process, the anode regime was used, which made it possible to accelerate the formation of the primary oxide layer on the surface of the samples. After two minutes of anodic treatment, the capacitor-state regime was started, as the most suitable for the formation of a coating with the reduction of micro stresses, which controls energy dissipation due to the coupling of mechanical and thermal fields.

Cross-sections were prepared by mechanical grinding and polishing on a LaboPol - 5 (Struers) machine using abrasive paper and a silicon oxide slurry. The microstructure of the cross-sections of the coating obtained was investigated using Quanta 200 scanning electron microscope (SEM) in the backscattered electron mode, with an accelerating voltage of 30 and $15 \mathrm{kV}$. The thickness and porosity of the coating were determined on a cross-sectional image using the Digimizer program.

The electrolyte of PEO consists of Potassium Hydroxide $(\mathrm{KOH})$ and Sodium Silicate $\left(\mathrm{Na}_{2} \mathrm{SiO}_{3}\right)$. In preliminary experiments various composition of the electrolyte was tested in terms of $\mathrm{KOH}$ content in the range from 4 to $20 \mathrm{~g} / \mathrm{L}$, and in terms of Sodium Silicate content in the range from 4 to $20 \mathrm{~g} / \mathrm{L}$. It was found that coatings with less porosity and maximal thickness are obtained in the range $6.4-9 \mathrm{~g} / \mathrm{L}$ for $\mathrm{KOH}$, and $5-10 \mathrm{~g} / \mathrm{L}$ for Sodium Silicate. So, this range was chosen for carrying out more detailed experiments to study the structure, elemental and phase composition, etc.

The study was carried out on five samples, the obtaining technological regimes of which are indicated in Table 1.

The duration of the processing was determined by a decrease in the intensity of the process, which means a possible transition of the process from the micro-arc stage to the arc stage. The last limitation is associated with the onset of etching and the destruction of the coating. The samples were cleaned with water for $3 \mathrm{~min}$ after treatment to prevent the deposition of electrolyte components during drying.

Table 1: The value of the thickness formed coating under different processing conditions

\begin{tabular}{|c|c|c|c|c|}
\hline \multirow{2}{*}{ Sample } & \multirow{2}{*}{$\mathrm{A} / \mathrm{dm}^{2}$} & \multirow{2}{*}{$\tau, \mathrm{min}$} & \multicolumn{2}{|c|}{ Electrolyte, $\mathrm{g} / \mathrm{L}$} \\
\cline { 3 - 5 } & \multicolumn{5}{|c|}{$\mathrm{KOH}$} & $\mathrm{Na}_{2} \mathrm{SiO}_{3}$ \\
\hline$M 0$ & \multicolumn{2}{|c|}{$\left(\mathrm{AlSi}_{12} \mathrm{Cu}\right)$ Without coating } \\
\hline$M 1$ & 30 & 120 & 9 & 10 \\
\hline$M 2$ & 30 & 120 & 9 & 5 \\
\hline$M 3$ & 22 & 120 & 6.4 & 10 \\
\hline$M 4$ & 22 & 120 & 9 & 10 \\
\hline$M 5$ & 22 & 120 & 6.4 & 5 \\
\hline
\end{tabular}
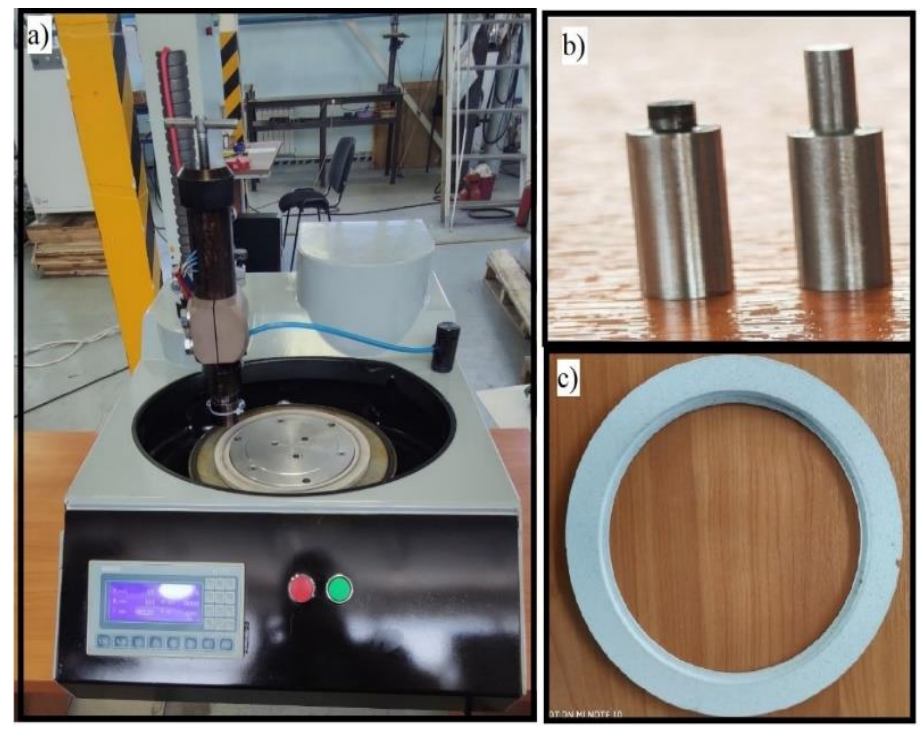

Figure 1: a) Image of the experimental setup for determining wear resistance; b) pin after testing (left), original (right) and c) coated substrate.

The 'pin on disc' wear testing machine used to study the mechanisms, wear rate and for determination of friction coefficients between the composite coating on a ring and the pin acting as a counterbody. The image of this machine is represented in Figure 1. Standard technical oil for a diesel engine was used as a lubricant for such wear tests. An aluminum alloy ring with a coating which deposited on its surface was fixed to the annular disc of the tribometer, and a $6 \mathrm{~mm}$ or $10 \mathrm{~mm}$ diameter cast iron pin was brought in contact. The load applied by the pin on the coating, as well as the rotation speed of the coated ring, were set and controlled during the experiment. The time of the experiment, the load on the pin, and the rotational speed of the coated ring 
were $180 \mathrm{~min}, 90 \mathrm{~N}$, and $1500 \mathrm{rpm}$, respectively fixed for all experiments. All tests were carried out at room temperature and atmospheric pressure. The wear rate was determined by evaluating the cross-sectional area of the wear grooves [11]. This data was obtained by analyzing the surface profile across the wear track using a SURTRONIC 25 profilometer. Wear rate was defined as volume loss under a unit load at a unit rotating distance.

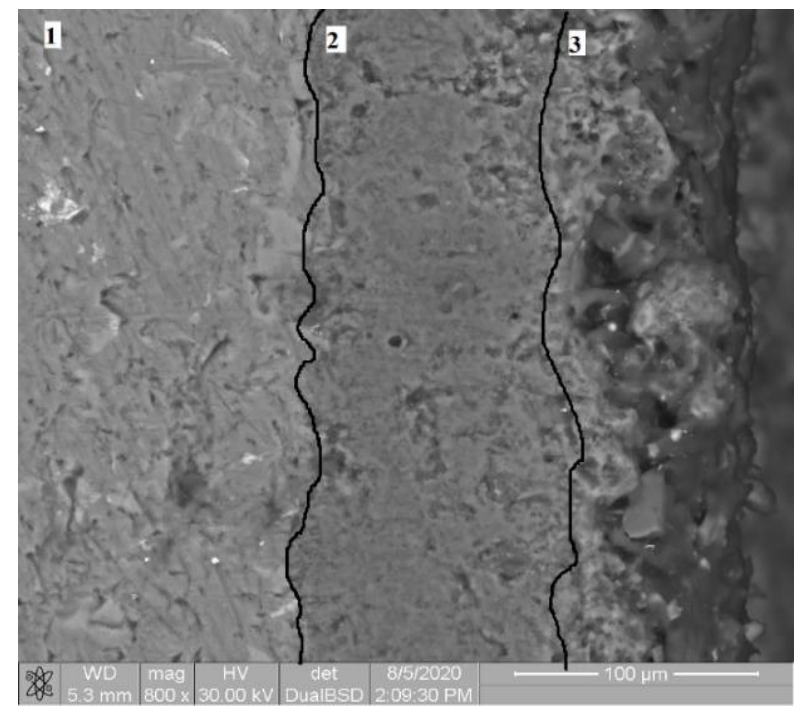

Figure 2: The coatings structure layers on the example of sample M1, obtained by the PEO method: 1-transition layer; 2- working layer; 3- technological layer.

\section{Results and Discussion}

SEM image of a cross-section of a sample $M 1$ with a $210 \mu \mathrm{m}$ thick coating on the AlSi12Cu aluminum alloy is shown in Fig. 2. The ceramic coating contains three layers: a $5 \mu \mathrm{m}$ thin transition layer, a $120 \mu \mathrm{m}$ thin working layer and a Technological layer with a thickness of $70 \mu \mathrm{m}$. The coatings obtained are characterized by good interfacial adhesion between the aluminum substrate and the ceramic coating. The same result was shown in previous work [12, 13]. Analyzing the cross-section image of the coatings show that the growth of the coating occurs in two directions. The first direction from the surface of the substrate to its depth (working layer) and this take place in the direction of the aluminum substrate, this forms a dense layer with good mechanical properties. The second one is the growth of the coating in the direction of the outer surface accompanied by the formation of a loose structure (Technological layer). The wear resistance of the coating obtained by the PEO method will be almost completely determined by the properties of the inner working layer. Therefore, the upper porous layer of the coatings was grinded to the working layer for tribological measurements, as well as for Xray phase studies.

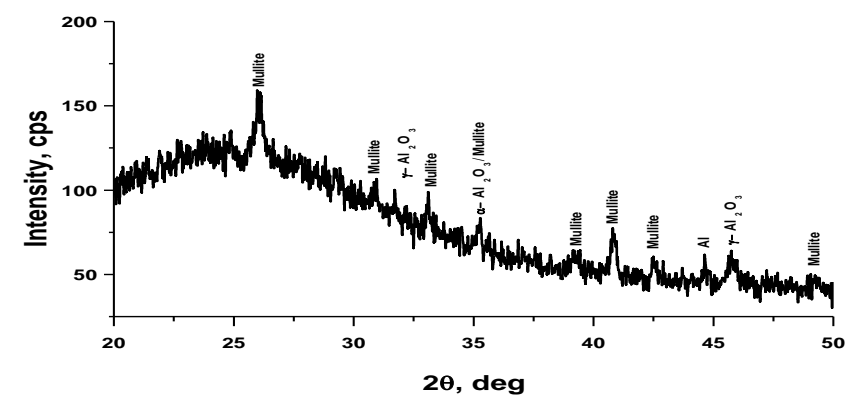

Figure 3: X-ray diffraction pattern of the technological layer of the coating applied according to mode sample $M 5$

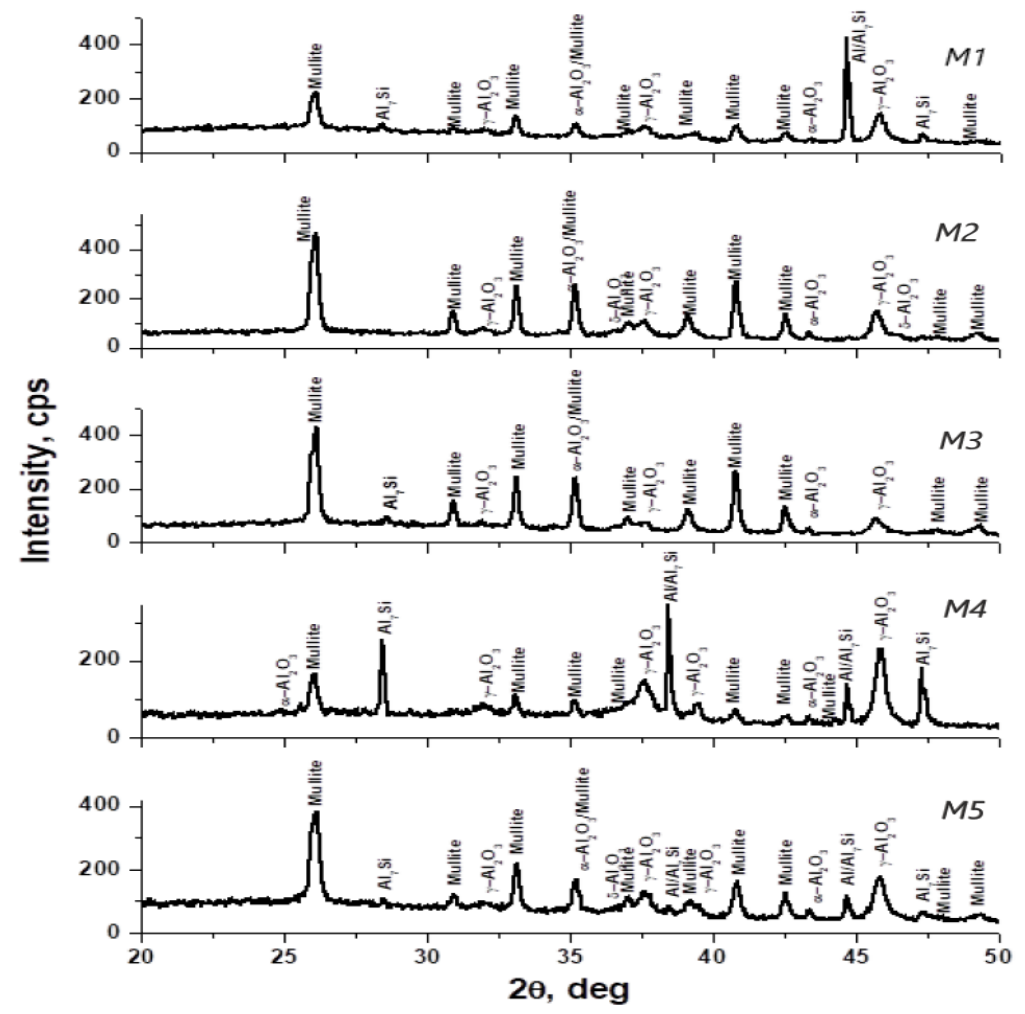

Figure 4: X-ray diffraction patterns of the working layer for applied coatings for the samples represented in table 1. 
In (Figure 4) X-ray phase studies have shown the absence of pure aluminum in the composition of the coatings. It is seen that the coatings obtained by the $P E O$ method on the $\mathrm{AlSi} 12 \mathrm{Cu}$ alloy consist mainly of 3 phases: $\alpha-\mathrm{Al}_{2} \mathrm{O}_{3}, \gamma-\mathrm{Al}_{2} \mathrm{O}_{3}$ and mullite. Diffraction reflections (105) $\alpha$, (200) $\gamma$, and (400) mullite with high reflection intensity are identified as characteristic diffraction peaks of $\alpha-\mathrm{Al}_{2} \mathrm{O}_{3}$ and $\gamma-\mathrm{Al}_{2} \mathrm{O}_{3}$, respectively. The working layer of the coating mainly consists of $\alpha-\mathrm{Al}_{2} \mathrm{O}_{3}$ phase the content of which is much higher than that of $\gamma-\mathrm{Al}_{2} \mathrm{O}_{3}$ (see Fig. 4 M2). It can be seen that the content of the $\alpha-\mathrm{Al}_{2} \mathrm{O}_{3}$ phase correspondingly increases from the working layer to the technological layer of the coating comparing the ratio of the intensities of reflection (105) $\alpha$ to reflection (200) $\gamma$ at different depths of the coating. We assumed that this is due to a change in the cooling rate of molten aluminum oxide in the microarc discharge channel [14].

The presence of porosity is a positive moment when the coating is operating under oil starvation conditions, the lubricant enters the pores of the coating and provides a permanent oil film. The value of volumetric porosity and average pore size for different coatings are represented in Figure 5.

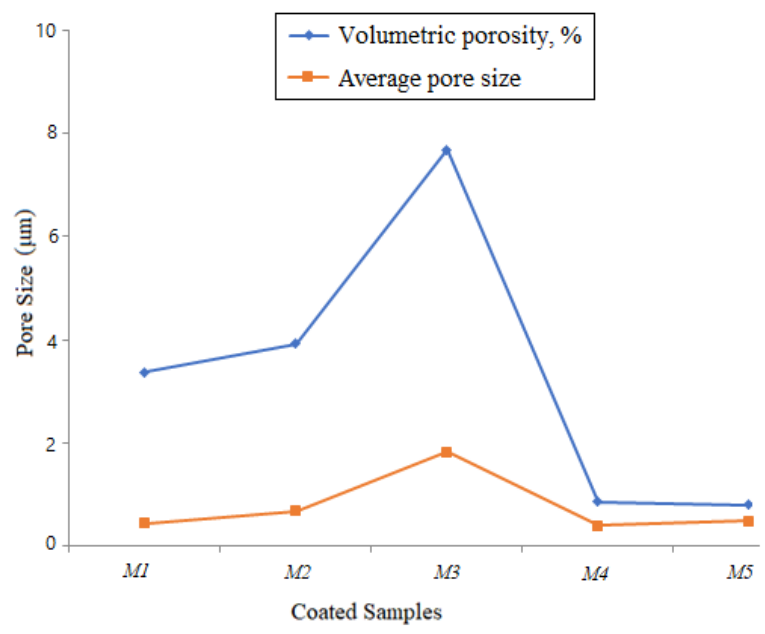

Figure 5: Volumetric porosity and average pore size of various processing modes.

The microhardness of the working layer is $1000-1500 \mathrm{HV}$ (Fig. 6). A piston with a coating based on oxyceramic with a hardness of $6.3-11.5 \mathrm{GPa}$ was tested in $[15,16]$. It was also found in previous works that the wear rate of coated pistons is 3.86 times lower than that of uncoated ones $[17,18]$.

Measurement of the microhardness of the applied coatings was carried out on cross-sections surfaces. This was done on the one hand, because it was impossible to make a correct measurement on the surface with the irregularity height comparable to diamond pyramid size and on the other hand it makes it possible to measure the change in microhardness over the thickness of the coating.

Figure 6 shows a graph of the distribution of the microhardness of the coating along with its thickness for example sample M3. Zero on the abscissa in this graph corresponds to the surface of the aluminum substrate on which the coating was applied. The microhardness of the coating increases first relatively slowly in the transition layer and then rapidly during the transition to the working layer until it reaches its maximum value at a depth of $40 \mu \mathrm{m}$ from the substrate-coating interface is 1600 $\mathrm{HV}$. After reaching the maximum value, it begins to gradually decrease with thickness increasing. The hardness of the coating does not exceed the value of $1600 \mathrm{HV}$ in the distances range of 25-100 $\mu \mathrm{m}$ from the $\mathrm{Al} / \mathrm{Al}_{2} \mathrm{O}_{3}$ interface. The microhardness of the aluminum alloy substrate near the $\mathrm{Al} / \mathrm{Al}_{2} \mathrm{O}_{3}$ interface is only $210 \mathrm{HV}$ [19] which is close to the hardness of $185 \mathrm{HV}$ in the substrate, measured far from the interface.

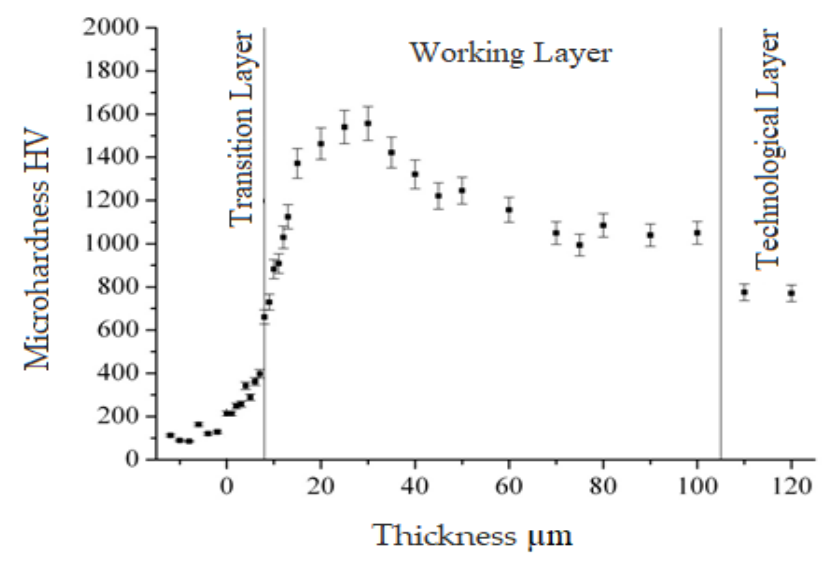

Figure 6: Typical distribution of microhardness over the coating thickness (shown for sample M3).

Figure 7 shows the cross-sectional profiles of the surface across the wear track of the a) initial substrate made of the AlSi12Cu alloy sample $M O$ and c) polished coating of the sample M5. The wear track of the substrate made of AlSi12Cu alloy as shown in Figure $7 \mathrm{~b}$ has a depth of $61 \mu \mathrm{m}$ and a height of $23.2 \mu \mathrm{m}$, which is much deeper than that of a coated ring whose depth is $30.9 \mu \mathrm{m}$ and a height of $6.9 \mu \mathrm{m}$ as shown in Figure $7 \mathrm{~d}$. This means that the surface wear rate decreases significantly after the coating deposition on the AlSi12Cu alloy by the PEO method. Figure $7 \mathrm{~b}$ shows the parabolic shaped profile of the wear groove with superficial changes in depth. This profile is formed with uniform abrasive wear of the material. Figure $7 \mathrm{~d}$, shows that there is no wear of the coating material over the entire width of the track, but instead there are narrow furrows that could occur if a very small fragment of the coating breaks off during testing and therefore forms a scratch in the area of the friction track.

Roughness profile parameters are showing in Figure 7. The roughness profile parameters for all samples were measured. It was observed that the maximum profile valley depth $(R v)$ and the average roughness $(R a)$ are more than two times higher for the uncoated sample in comparison to the coated one.

As it was mentioned above, the coatings were ground to remove the transition loose layer, which has poor mechanical properties. Since the thickness of the transition and the working layers were different for different samples and it was necessary to grind different amounts of materials. As a result, the remaining coating thickness was different for different samples. So, the microhardness distribution over the thickness (the thickness was determined from the interface between the metallic substrate and the coating) was carried out for different sample thicknesses. Table 2 shows the value of the coating wear rate for different samples obtained at a fixed operating time and applied load. It was 
found that the smallest wear rate for coating samples is only $3.4295 \times 10^{-7} \mathrm{~mm}^{3} / \mathrm{Nm}$, which is a thousand times less than for the uncoated $\mathrm{Al}$ substrate. This means that the wear resistance surface of an aluminum alloy by $P E O$ can be improved by three orders of magnitude by oxide coating deposition. The loss of coating thickness during the wear test is much less than the thickness of their working layer, so table 2 describes the results of wear of the working layers of coatings.

As shown for coating samples $M 2$ - M5, the wear rate gradually decreases as the remaining coating thickness decreases.

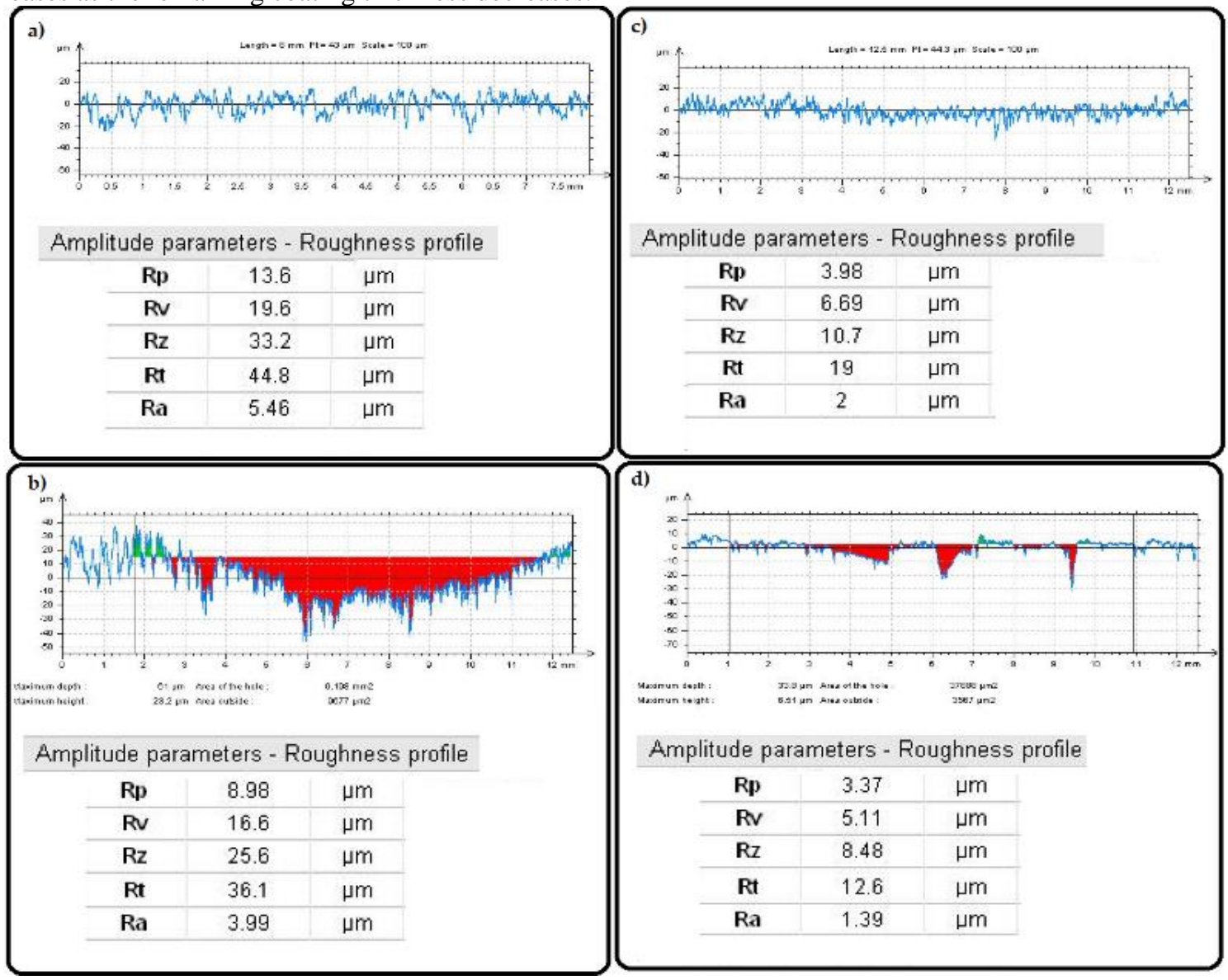

Figure 7: Typical cross-sectional profiles of the surface on an aluminum substrate (sample $M 0$ ) before wear track (a); across the wear track (b); and on the polished coating with a remaining thickness of $180 \mu \mathrm{m}$ (sample M2) before wear track (c); across the wear track (d).

Table 2: Wear rate of a substrate without coating and polished coating by tribological parameters.

\begin{tabular}{|c|c|c|c|c|c|}
\hline Sample & $\begin{array}{c}\text { Coating thickness } \\
(\mu \mathrm{m})\end{array}$ & $\begin{array}{c}\text { Loss of thickness in } \\
\text { friction track }(\mu \mathrm{m})\end{array}$ & $\begin{array}{c}\text { Wearing time } \\
(\mathrm{min})\end{array}$ & $\begin{array}{c}\text { Wear load } \\
(\mathrm{N})\end{array}$ & $\begin{array}{c}\text { Wear rate } \\
\left(\mathrm{mm}^{3} / \mathrm{Nm}\right)\end{array}$ \\
\hline$M 0$ & 0 & 50 & 180 & 90 & $8.73016 \times 10^{-4}$ \\
\hline$M 1$ & 210 & 38 & 180 & 90 & $1.38973 \times 10^{-6}$ \\
\hline$M 2$ & 180 & 29 & 180 & 90 & $2.54766 \times 10^{-7}$ \\
\hline$M 3$ & 160 & 27 & 180 & 90 & $3.4295 \times 10^{-7}$ \\
\hline$M 4$ & 80 & 14 & 180 & 90 & $1.6183 \times 10^{-6}$ \\
\hline$M 5$ & 90 & 10 & 180 & 90 & $1.4610 \times 10^{-6}$ \\
\hline
\end{tabular}


The change of the friction coefficient for sample $M 2$ is paired with a cast iron pin depending on the time of wear is shown in Fig. 8. In the first minutes of the experiment, the lapping of a pair of rubbing bodies occurs. At this time, the contact area changes (increases), primary chips are formed, which in total leads to an increase of the friction coefficient up to 0.85 . During 15 minutes of wear, the coefficient of friction $(\mu)$ is still high and remains at the level of about 0.75 . At this stage, there is an intensive formation of $\alpha-\mathrm{Al}_{2} \mathrm{O}_{3}$ and $\gamma-\mathrm{Al}_{2} \mathrm{O}_{3}$ microparticles, which cause intensive wear of both the coating and the counter body. This leads to the expansion and deepening of the wear mark on the coating. At the same time, there is an intensive formation of metal chips of the counter body material. In addition, the ceramic grains of $\alpha-\mathrm{Al}_{2} \mathrm{O}_{3}$ and $\gamma-\mathrm{Al}_{2} \mathrm{O}_{3}$ in the coating become smoother, and part of the metal chips is driven into the pores of the coating. Thus, at this stage, the coefficient of friction remains at a high level. As we continue the experiment, the metal particles from the pin become clogged in the pores of the ceramic coating, which leads to the fact that the ceramic-to-metal contact turns into a metal-tometal contact, as a result of which the coefficient of friction decreases. This contact looks like a thin lubricating layer of cast iron, which creates a lubricating effect between the pin and disc. In this case, the wear loss is very small, which results in a very low wear rate of coatings with longer test times.

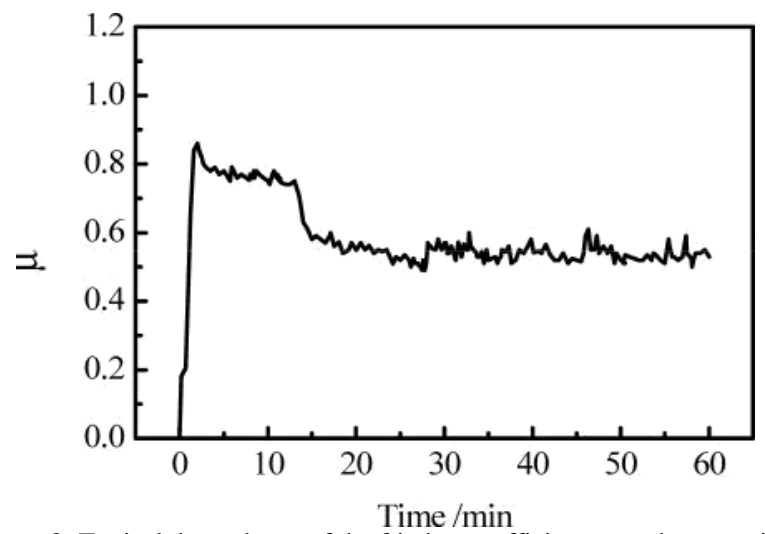

Figure 8: Typical dependence of the friction coefficient $\mu$ on the wear time (measured at $M 1$ ).

Figure 9 and 10 shows images of signs of wear on the coating and the counterbody. As shown in figure 9, a wide wear path is formed in the tribological contact zone. The wear mark shows many grooves, which corresponds to the profile in Fig. 7. These grooves are the result of abrasive wear by small particles that have broken off from the coating. The wear trace of the counterbody as shown in figure 10 have more cracks than the coated ring because the hardness of a cast iron rod is less than oxide coating.

\section{Conclusions}

Wear tests were performed using standard technical oil for a diesel engine as a lubricant. The wear rates of the coatings and counterbody, as well as the friction coefficients for each condition at a normal load of $90 \mathrm{~N}$ for $180 \mathrm{~min}$, were obtained. SEM and $X R D$ were used to analyze the effect of process parameters and we founded that the best range of electrolyte composition for $\mathrm{KOH}$ (6.4-9 g/L) and $\mathrm{Na}_{2} \mathrm{SiO}_{3}(5-10 \mathrm{~g} / \mathrm{L})$ in order to get volumetric porosity less than $1 \%$ and hardness more than 1600 HV. Depend on in the intensity of the PEO process the selected time was $120 \mathrm{~min}$ and current density was in range $(22-30 \mathrm{~A} /$ $\mathrm{dm} 2$ ). When time or current density of Poe process increased this led to destruction of the coatings. A comparative analysis of the structure of experimental samples allows us to conclude that it is possible to provide different properties of coatings on the same material. In particular, the experimental sample M5 has low porosity and a working layer thickness of $90 \mu \mathrm{m}$; therefore, it has higher mechanical strength and wears resistance. This makes the coating most suitable for resizing and increasing the wear resistance of the piston skirt.

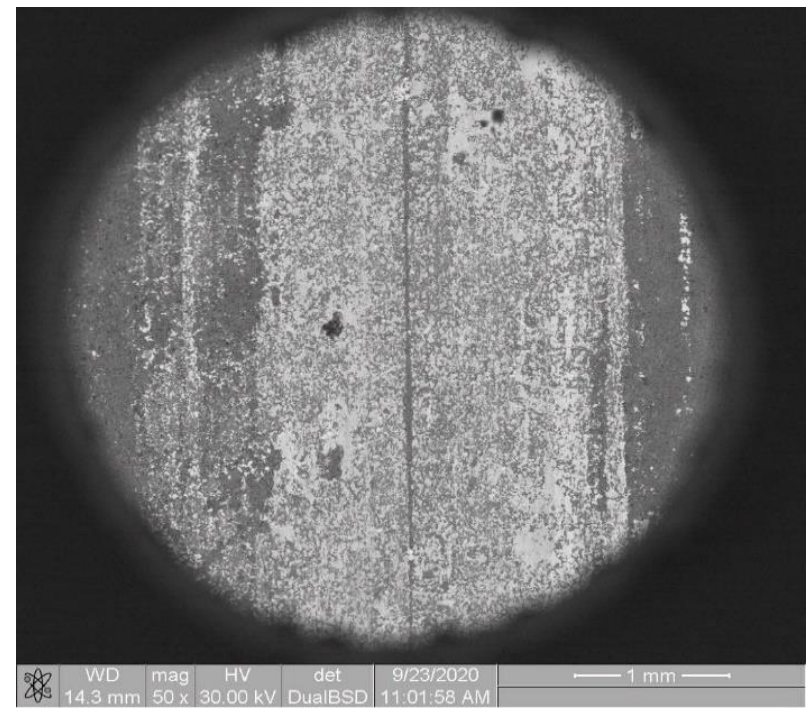

Figure 9: Electron microscopic images of the surface of the wear track for the aluminum coating sample $M 4$

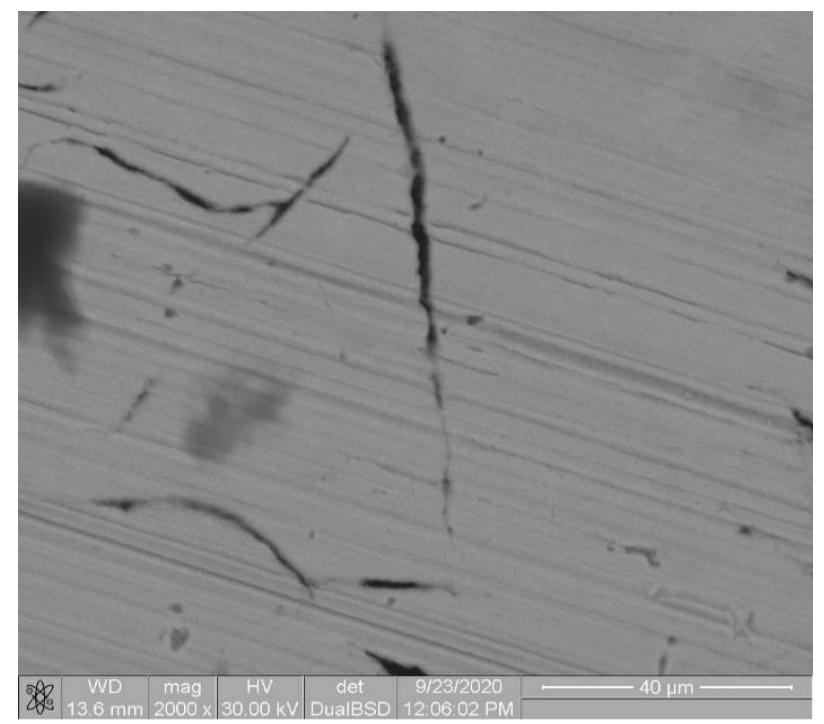

Figure 10: the wear track surface for the counterbody

It was found that the maximum profile valley depth $(R v)$ and the average roughness $(R a)$ for the uncoated sample are more than two times higher in comparison to other samples. Reducing roughness should have a positive effect on engine performance. The wear rate of the samples with oxide coatings is three orders of magnitude less than for uncoated one. Also, coefficient friction of coated samples was less than 0.04 .

The M5 sample has the best thermal insulation characteristics, which combines a low porosity about $10 \%$ depending on the concentration of $\mathrm{Na}_{2} \mathrm{SiO}_{3}$. In addition, the $\mathrm{M} 5$ 
sample compared to the other samples is more cost-effective in terms of the electrolyte composition. It is also noted that the wear loss of this sample is less than that of others, which is a consequence of the higher hardness.

Thus, it has been established that by the method of plasma electrolytic oxidation it is possible to obtain high-quality wearresistant and heat-protective coatings on aluminum alloys with the high silicon content. By varying the technological modes and composition of the electrolyte, it is possible to change the structure, composition and thicknesses of coatings in a wide range from 80 to $300(\mu \mathrm{m})$.

\section{References}

[1] M.S.H. Al-Bdeiri, "Review of electroplating-plasma modification methods for the production of anodized coatings on aluminum alloys: microstructure, properties and applications," Bulletin PNRPU. Mechanical engineering, materials science, 22(3), 51-59, doi: 10.15593/2224-9877/2020.3.07

[2] G. Lv, W. Gu, H. Chen, W. Feng, M.L. Khosa, L. Li, E. Niu, G. Zhang, S.Z. Yang, "Characteristic of ceramic coatings on aluminum by plasma electrolytic oxidation in silicate and phosphate electrolyte," Applied Surface Science, 253(5), 2947-2952, 2006. doi:10.1016/j.apsusc.2006.06.036

[3] S. Sergeev, M.S. Albieri, V. Yatsenko, D. Natalya, "Theoretical and practical study of possibility to decrease thermal stress in pistons of internal combustion diesel engine by using galvanic plasma modification," International Journal of Advanced Science and Technology, 28(8), 2019. doi:10.13140/RG.2.2.32284.44162

[4] Y. Zong, R.G. Song, T.S. Hua, S.W. Cai, C. Wang, H. Li, "Effects of current frequency on the MAO coatings on AA7050," Surface Engineering, 36(8), 809-816, 2020. doi:10.1080/02670844.2019.1596577

[5] S. Xin, L. Song, R. Zhao, X. Hu, "Influence of cathodic current on composition, structure and properties of $\mathrm{Al} 2 \mathrm{O} 3$ coatings on aluminum alloy prepared by micro-arc oxidation process," Thin Solid Films, 515(1), 326332, 2006. doi:10.1016/j.tsf.2005.12.087

[6] A. Polat, M. Makaraci, M. Usta, "Influence of sodium silicate concentration on structural and tribological properties of microarc oxidation coatings on 2017A aluminum alloy substrate," Journal of Alloys and Compounds, 504(2), 519-526, 2010, doi:10.1016/j.jallcom.2010.06.008

[7] V. Dehnavi, B.L. Luan, X.Y. Liu, D.W. Shoesmith, S. Rohani, "Correlation between plasma electrolytic oxidation treatment stages and coating microstructure on aluminum under unipolar pulsed DC mode," Surface and Coatings Technology, 269, 91-99, 2015. doi: 10.1016/j.surfcoat.2014.11.007

[8] Y.-C. Lin, Y.-H. Chen, "Study on Tribological Behavior of Surface Microarc Oxidation 6061 Aluminum Alloy," in 2019 IEEE 6th International Conference on Industrial Engineering and Applications (ICIEA), 883-887, 2019. doi:10.1109/IEA.2019.8714909

[9] A.L. Yerokhin, V. V Lyubimov, R. V Ashitkov, "Phase formation in ceramic coatings during plasma electrolytic oxidation of aluminium alloys," Ceramics International, 24(1), 1-6, 1998, doi: 10.1016/S02728842(96)00067-3

[10] L. Agureev, S. Savushkina, A. Ashmarin, A. Borisov, A. Apelfeld, K. Anikin, N. Tkachenko, M. Gerasimov, A. Shcherbakov, V. Ignatenko, others, "Study of plasma electrolytic oxidation coatings on aluminum composites," Metals, 8(6), 459, 2018, doi:10.3390/met8060459

[11] S. SV, M.S. Al-Bdieri, N.A. Dubrovina, "Surface modification of the AK12MMGH aluminum alloy by micro-oxidation technique to improve operating characteristics," Metallurgy, 27(1), 217-223, 2020, doi: 10.34759/vst-2020-1-217-223.

[12] S. V Sergeyev, M.S. Al-Bdeiri, O.B. Beshevli, "Development of a technique for surface treatment of a rotary machine." International Journal of Engineering Trends and Technology, 68(9), 31-35, 2020, doi: 10.14445/22315381/IJETT-V68I1P201

[13] J.A. Curran, T.W. Clyne, "Porosity in plasma electrolytic oxide coatings," Acta Materialia, 54(7), 1985-1993, $2006 . \quad$ doi: 10.1016/j.surfcoat.2004.09.037

[14] P.L. Menezes, "Surface texturing to control friction and wear for energy efficiency and sustainability," The International Journal of Advanced Manufacturing Technology, 85(5-8), 1385-1394, $2016 . \quad$ doi: 10.1007/s00170-015-8058-2

[15] W. Wang, C. Han, "Microstructure and Wear Resistance of Ti6Al4V
Coating Fabricated by Electro-Spark Deposition,” Metals, 9(1), 23, 2019, doi:10.3390/met9010023

[16] S.K. Singh, S. Chattopadhyaya, A. Pramanik, S. Kumar, A.K. Basak, "Effect of lubrication on the wear behaviour of CrN coating deposited by PVD process," International Journal of Surface Science and Engineering, 13(1), 60-78, 2019, doi: 10.1504/IJSURFSE.2019.097938

[17] B. Haghighat-Shishavan, R. Azari-Khosrowshahi, S. Haghighat-Shishavan, M. Nazarian-Samani, N. Parvini-Ahmadi, "Improving wear and corrosion properties of alumina coating on AA7075 aluminum by plasma electrolytic oxidation: Effects of graphite absorption," Applied Surface Science, 481, 108-119, 2019, doi: 10.1016/j.apsusc.2019.03.069

[18] M.Sh. Al-Bdeiri, V.V. Krasilnikov, S.V. Sergeev, "A modified quasistationary method for studying the change in transition temperatures of diesel engine pistons coated with heat-shielding materials," 24(5), 954-965, 2020, doi:10.21285/1814-3520-2020-5-954-965

[19] Q. Li, J. Liang, B. Liu, Z. Peng, Q. Wang, "Effects of cathodic voltages on structure and wear resistance of plasma electrolytic oxidation coatings formed on aluminium alloy," Applied Surface Science, 297, 176-181, 2014, doi: org/10.1016/j.apsusc.2014.01.120 